\title{
Without Mercy
}

Jordi Casabona ${ }^{1}$

Between electric gloom, angels and demons dressed in plastic blue

have dragged me through the darkness, to the infinite black stone, where the origin and the end of time are lost.

There, in the immense dark solitude, and in the imposed silence of word and thought, She, in my breath, gazed at me with her eyes of fire, frosty and timeless, without any mercy, without any mercy.

\section{About the Author}

Dr. Casabona is a medical epidemiologist and scientific director of the Centre d'Estudis Epidemiològics de VIH/ SIDA/ITS de Catalunya (CEEISCAT), Barcelona, Spain.
He has devoted his career working on HIV/STIs both at the local and international level. He is also a writer, having published 3 poetry books.

\section{Bibliography}

1. Casabona J. The island of despair. Ann Infect Dis Epidemiol. 2020;5:1061.

Address for correspondence: Jordi Casabona, CEEISCAT, Josep Carreras Building, Ctra. de Can Ruti, Camí de les Escoles, s/n, Badalona 08916, Spain; email: jcasabona@iconcologia.net

Author affiliation: Campus de Can Ruti, Badalona, Spain

DOI: https://doi.org/eid10.3201/eid2703.203690
${ }^{1}$ The author wrote this poem, originally in Catalan, during the first days of his hospitalization because of coronavirus disease in March 2020 during the first wave in Spain. 